\title{
Pieris rapae in Mid-ocean.
}

Dr. J. L. LeConte recently sent me a butterfly taken last August, by Dr. R. H. Lamborn, on the steamship Abyssinia, eleven hundred miles east of New York, while on her passage from Liverpool. When first seen, Dr. Lamborn writes, the insect was "flying among the rigging and following the ship, which was moving over a calm sea at the rate of about twelve miles an hour. The wind had been steadily south-west during the passage." This butterfly is a female of Pieris rapae, and is in perfect condition, excepting that it was rubbed in capture.

This throws light, if any were needed, on the manner of the introduction of this pest into America. Undoubtedly the butterfly had not flown from land, but the caterpillar from which it sprang had been introduced into the vessel in the cabbages intended as food while in port or during the voyage; and in this particular instance the butterfly had emerged from the chrysalis (which had suspended itself in some safe nook on board) previous to the completion of the voyage. This must now be a weekly occurrence in midsummer, and it would seem as if no amount of precaution, likely to be taken, would have kept Pieris rapae out of America many years longer. I have evidence that the insect was independently introduced into the port of New York, and swarmed in the vicinity of that city, before the Canadian hordes had reached Albany, on their southward march.

Samuel H. Seudder.

Hibernation of Amphipyra pyramidoides. In Chicago, Illinois, this insect is single-brooded, for a poplar-feeding larva found the latter part of May, and which spun upon the 14th of June, did not produce the moth till the following April ; but specimens obtained near St. Louis often produce the moth during July of the same year that they are found as worms. In this last case a second brood is doubtless prorluced the same year, though it is barely possible that the moths winter over and do not deposit till spring; for they are characterized by having very flat bodies, and with their wings folded flatly on their backs they are often found hiding in narrow cracks and crevices where they seem to love to shelter.-3rd Mo. Ent. Rep., p. 73.

The above, written in 1870 , shows conclusively that this insect sometimes passes the winter in the chrysalis state. My experience, since, agrees with Mr. Roland Thaxter's, and I have no doubt that the species frequently hibernates also as a moth. There is much greater irregularity in the development, time of appearance, and hibernation of insects than most entomologists incline to allow.

C. V. Riley.

No. 22 was issued March 6, 1876. 

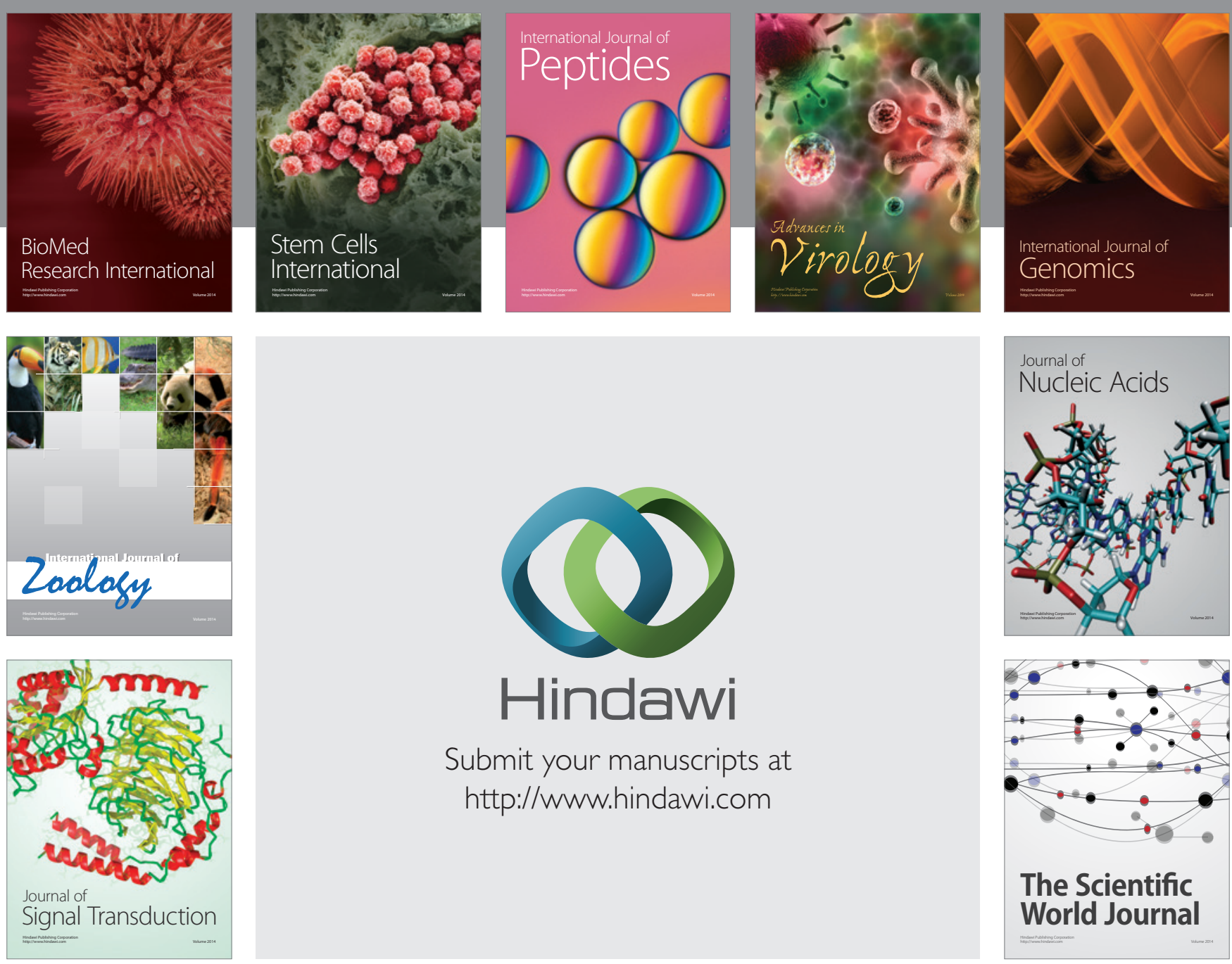

Submit your manuscripts at

http://www.hindawi.com
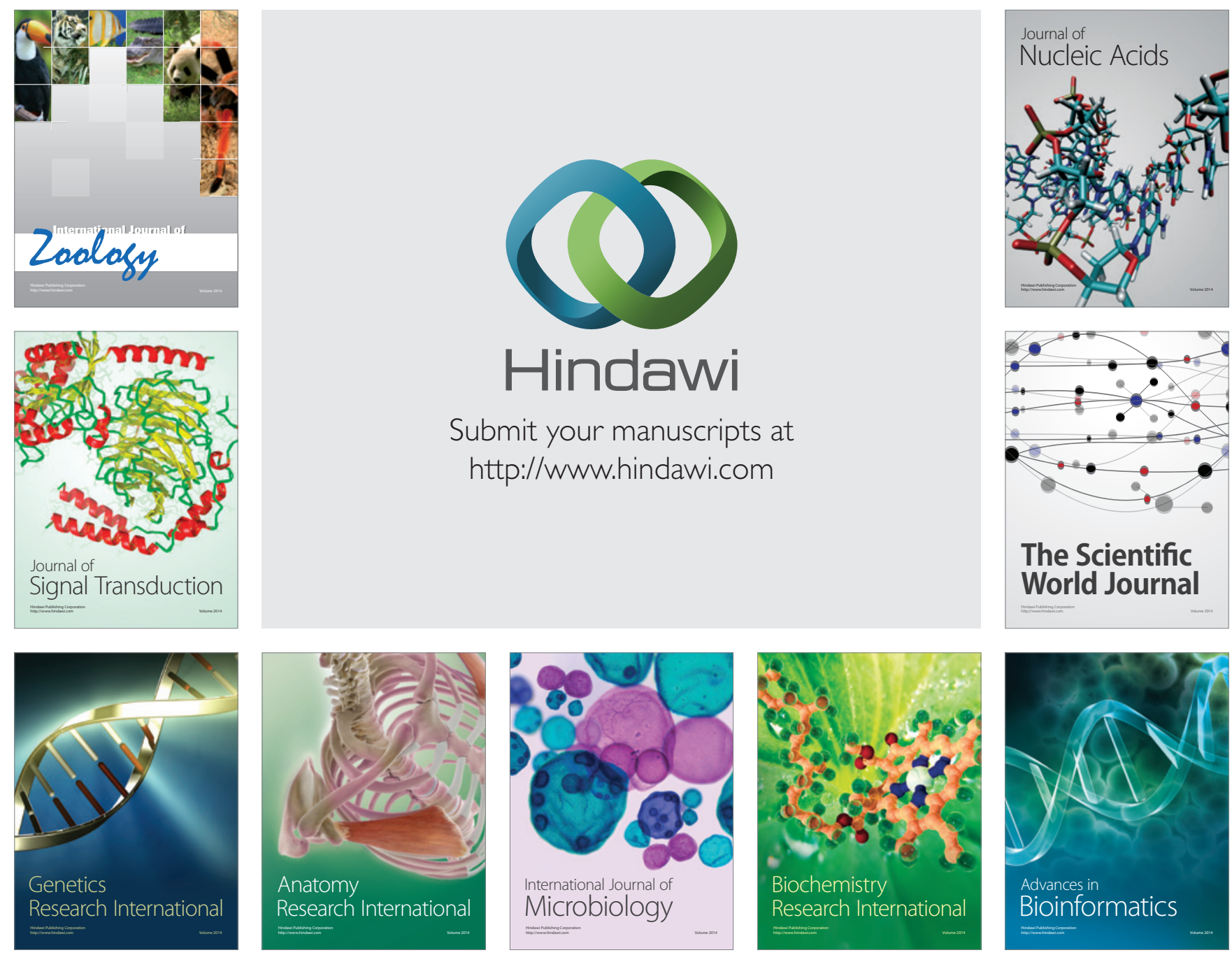

The Scientific World Journal
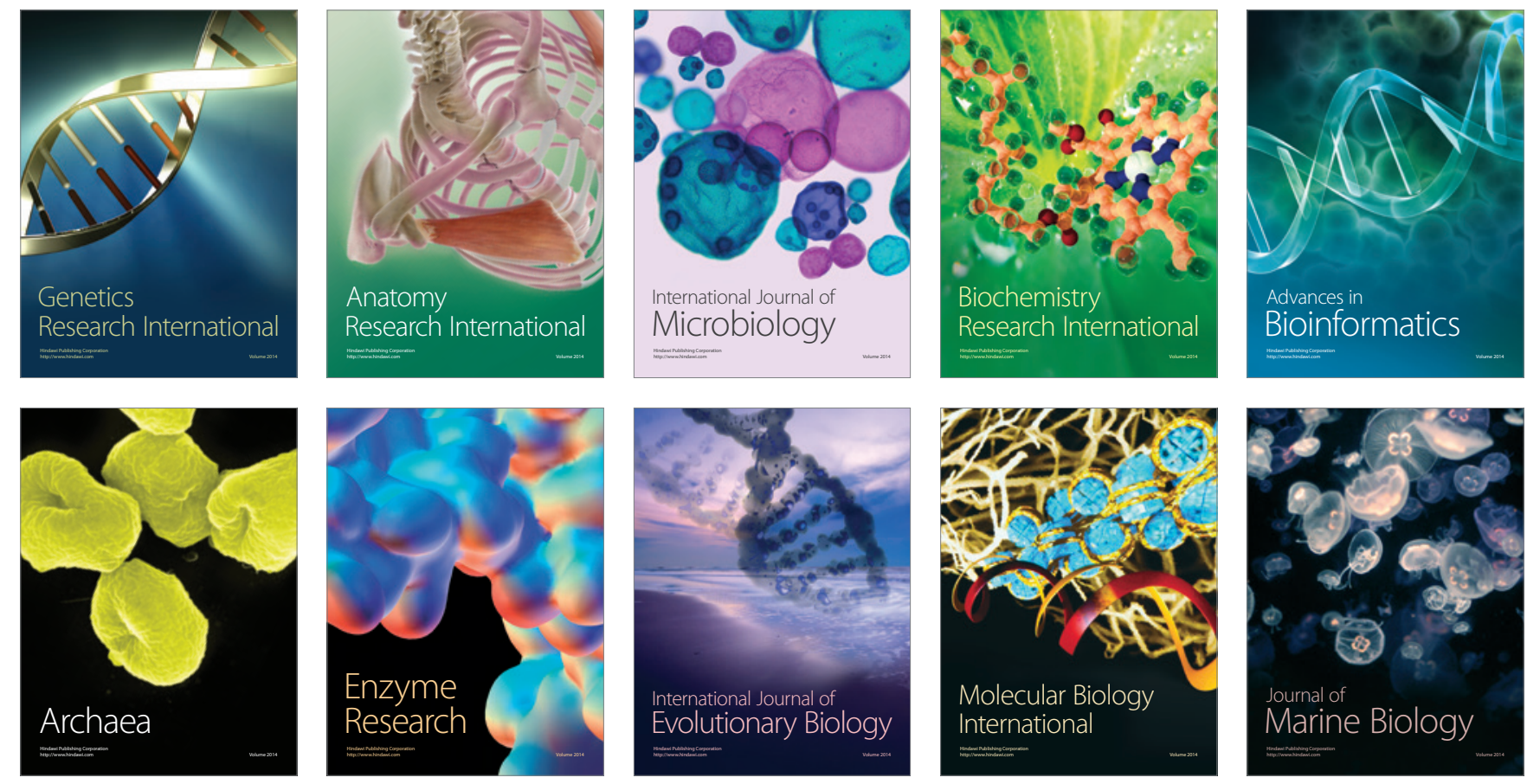